\title{
Wastewater as a Heat Source for Individual Residence Heating: A Techno-economic Feasibility Study in the Brussels Capital Region
}

\author{
Jan Spriet ${ }^{* 1}$, Patrick Hendrick ${ }^{2}$ \\ ${ }^{1}$ Aero-Thermo-Mechanics, Université Libre de Bruxelles, F. D. Roosevelt Avenue 50, \\ 1050 Brussels, Belgium \\ e-mail: jspriet@ulb.ac.be \\ ${ }^{2}$ Aero-Thermo-Mechanics, Université Libre de Bruxelles, F. D. Roosevelt Avenue 50, \\ 1050 Brussels, Belgium \\ e-mail: patrick.hendrick@ulb.ac.be
}

\begin{abstract}
Cite as: Spriet, J., Hendrick, P., Wastewater as a Heat Source for Individual Residence Heating: A Techno-economic Feasibility Study in the Brussels Capital Region, J. sustain. dev. energy water environ. syst., 5(3), pp 289-308, 2017, DOI: http://dx.doi.org/10.13044/j.sdewes.d5.0148
\end{abstract}

\begin{abstract}
A large part of the thermal energy in buildings is lost through the drain and ends up as warm wastewater in the sewer system. The installation of heat exchangers in the sewer system enables a rise of the source temperature of heat pumps, increasing their coefficient of performance. To investigate the potential of such a technique in the Brussels Capital Region, a test facility named MYRTES has been installed in the sewer network, the starting point of this facility being to have one heat recovery system per residence. To estimate the heat recovery rate, potentially available in the Brussels Capital Region, the data from this test facility have been used as inputs and validation for a predictive model, considering both the heat recovery and its financial and environmental implications. Simulations show a minimum heating power of the heat pump of $6.3 \mathrm{~kW}$, at a hot water temperature of $45{ }^{\circ} \mathrm{C}$. A maximum of $35 \%$ of the buildings in the Brussels Capital Region are eligible for the use of such a system. At current tariffs, the levelized cost of energy for these systems, is lower than for traditional air heat pumps, but is higher than for gas boiler systems. The total equivalent warming impact, however, is estimated to be around $49 \%$ lower than for gas boiler systems and around 13\% lower than for air heat pumps. In conclusion, heating through these types of systems is more expensive than gas boiler systems, but with increased consumption the competitiveness of these systems improves.
\end{abstract}

\section{KEYWORDS}

Individual residence heating, Observations on municipal sewer systems, Wastewater heat recovery, Competitiveness assessment, Total equivalent warming impact of heating systems.

\section{INTRODUCTION}

In Belgium the current consumption of thermal energy in buildings represents roughly $20-25 \%$ of the energy consumption of households [1]. In [2] the evolution of thermal energy consumption in buildings is described, showing that efforts to reduce this thermal energy consumption, and thus increase the energy efficiency, have been going on since the 1980s, resulting in a reduction of consumption by $10-30 \%$. However, still a

* Corresponding author 
large part of the thermal energy (around 15\%) is lost through the drain and sewer system (up to $30 \%$ in low-energy buildings). In modern times, the heat lost through the drain represents the largest source of heat loss in buildings. The reduction in energy intensity of the heating system, using heat pumps, as compared to other systems is described in [3]; however a gas boiler system is not considered in this case.

The production of hot water, for either sanitary use or space heating, accounts for around $17 \%$ (up to $50 \%$ in low-energy buildings) of the thermal energy consumption in buildings [4]. In a modern house the heat losses through wastewater imply a Carbon dioxide $\left(\mathrm{CO}_{2}\right)$ emission of over $450 \mathrm{~kg}$ per year, as stated in [5]. Furthermore, a comfort temperature of the room of $20^{\circ} \mathrm{C}$ is not very high, and when classical radiator systems are used, a large amount of energy is needed to generate high-temperature water for heating. The cooling of this water is low, and water with a high energetic and exergetic value is simply flushed out of the building $[4,6]$. Wastewater can be used as a heat source for low temperature heating systems.

Using a source of energy loss as a source for an energy consuming component of the heating system reduces the energy consumption of buildings. Recovering heat from wastewater, in order to heat sanitary and space-heating water, is thus a promising project in order to improve the energy efficiency in buildings, and the energy efficiency of the water cycle. When both the thermal and the chemical energy of the wastewater are utilized it is feasible to reach an energy-neutral water cycle [7]. Following a similar thought process, [8] describes the use of heat pumps with an in-house circuit, in this case the heating system.

Systems utilizing sewage water or wastewater as a heat source have already been described extensively in literature. In 2005 a study was published to use wastewater from a hotel as a heat source [9]. An overview of different possibilities and set-ups is given in $[2,10,11]$, as are some examples of different existing facilities in Norway and Switzerland using a heat exchanger over sewer sections of several hundreds of meters. The heat recovery from drainage systems in large public shower facilities is described in [12], and experimental observations from a heat recovery system in a spa centre is described in [13]. The experimental performance of a dry-expansion evaporator, for a wastewater source heat pump is described in [14]. These wastewater heat recovery systems can be installed within the houses, in the sewer system, or at wastewater treatment plants. The latter two options are easier to arrange, and allow for a distribution over a larger area [7]. An example of a study concerning in-house heat recovery from shower effluent in residential buildings is described in [13]. In-house heat recovery from public shower facilities is described in $[15,16]$, the particularity in this case is that the heat recovery is twofold, once for preheating the hot water, and a second time as a heat source for the evaporator of the heat pump. This is only possible with a higher temperature of this non-mixed effluent $\left(30^{\circ} \mathrm{C}\right)$.

District heating and cooling will play an important part in sustainable energy systems. They should become a part of smart energy systems, combining not only heating and cooling, but also electricity and transport. Recovering heat from wastewater can both improve the energy efficiency of the building, and create a heat source for space heating. Coordinating both is listed as an important parameter for the $4^{\text {th }}$ generation of district heating $[17,18]$. The hybridisation of heat sources in district heating networks is also described in [19]. This paper claims that a diversification in the heat sources of a heating network leads to reduced heat production costs, and increased flexibility, recovering heat from wastewater and could serve as an additional source for heating networks.

This technology has already been employed successfully on multiple sites in, amongst others, Switzerland and Norway, where installations have been working successfully for over 30 years, as described in [2, 20]. These sites show a very high performance of these wastewater heat recovery systems, with systems recovering up to 
$400 \mathrm{MWh}$, and heating powers provided up to $700 \mathrm{~kW}$. The COP of these systems reaches amaximum value of 7 .

The above mentioned systems all implement a heat exchanger in a newly built wastewater system, and over lengths in excess of $100 \mathrm{~m}$. This allows for appropriate dimensioning of the pipes and/or canals, in order to fit in the heat exchanger, but also allows for adaptation of the size of the heat exchanger to the heating demand. The retrofitting of a heat recovery system in existing sewer systems is not discussed in these papers.

Studies of the wastewater temperature in a general sewer system have been documented in Bejing, China [21], Bologna, Italy [22], Sala, Sweden [23] and in Zurich, Switzerland [2]. These studies show a temperature between 8 and $25{ }^{\circ} \mathrm{C}$, which is insufficient to directly heat water for sanitary use or space heating. Therefore the wastewater should be used as a low temperature heat source for heat pumps, as in the case for the systems described in $[2,10-13,20]$.

Most of the above mentioned papers dismiss the possibility of utilizing heat recovery systems from wastewater for the heating of individual residences, claiming that it is financially nonviable in the conditions present at the sites of these studies. However they also show the significant impact of the different local characteristics of the sewer network on economic and technical feasibility. This paper investigates the feasibility of heating individual households with heat recovered from sewers, as opposed to heating large consumers or heating networks. The study focuses on the case of the Brussels Capital Region. The objective is to investigate the feasibility of employing low-cost, small size (approx: $6 \mathrm{~m}$ ) heat exchangers, in combination with small power (approx: $6 \mathrm{~kW}$ ) heat pumps, used for the heating of individual residences. The final aim of the larger project is to provide a solution to retrofit the sewer network of the region with these low-cost heat exchangers, installing them at scheduled renovations and maintenance works. This way installation cost, and general disturbance due to works can be reduced.

\section{MYRTES TEST FACILITY}

The wastewater serves as a low temperature source for heat pumps. The system is shown in Figure 1. The primary fluid of the heat pump (which, for the case of the MYRTES test facility, is glycolated water (MEG 33\%) flows through a heat exchanger placed in the sewer, recovering the heat from wastewater. In turn it yields its heat to the secondary fluid in the evaporator of the heat pump. The heat pump is used in a classical way, in order to heat the water circulating in the space heating circuit.

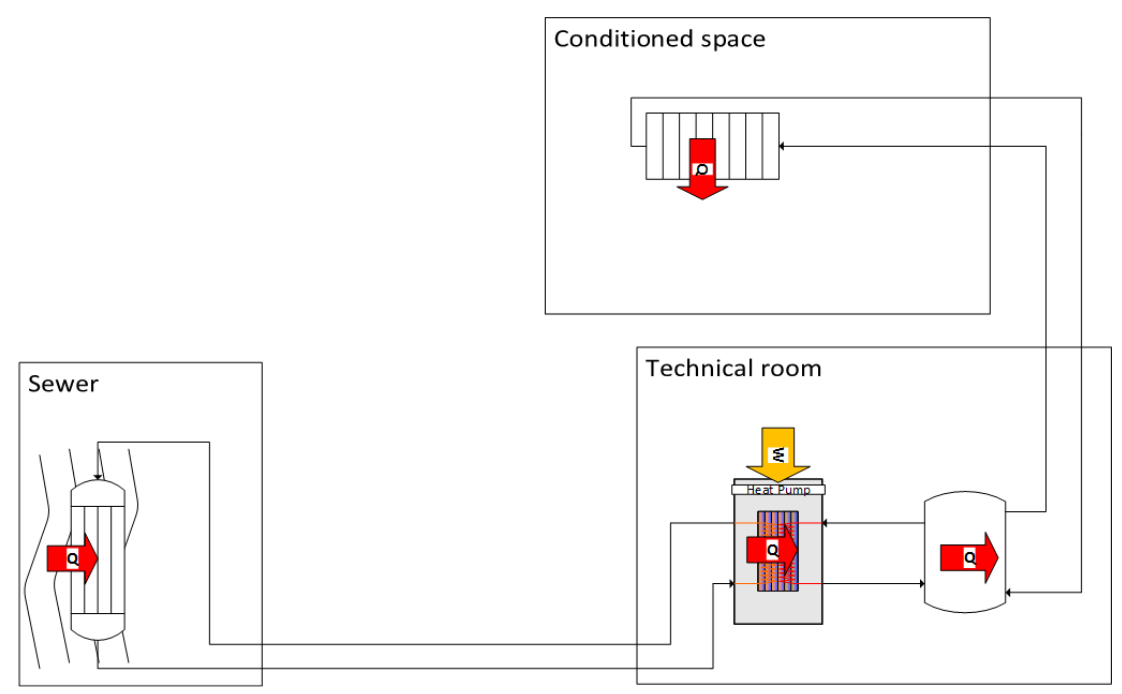

Figure 1. General scheme of a heat recovery system from wastewater 
For the case in the Brussels Capital Region, the strategy for recovering heat is to install heat exchangers at the lowest possible cost, even if this means reducing the efficiency of heat recovery, and thus requiring larger exchange surfaces. In order to do this, heat exchangers would be placed while renovating the sewers. This reasoning led to high density polyethylene as the material for the heat exchanger, although this material has poor conduction properties, and thus limits the potential heat exchange. Some general characteristics of the employed heat exchanger are given in Table 1. The installed heat pump is a Stiebel-Eltron WPF 5.

Table 1. General characteristics of the installed heat exchanger

\begin{tabular}{c|c}
\hline Heat exchanger type & Multi-pass \\
Length of the heat exchanger & $6 \mathrm{~m}$ \\
Heat exchange surface & $10.26 \mathrm{~m}^{2}$ \\
Material & PEHD100 SDR17 DN32 \\
\hline
\end{tabular}

A test case, using a prototype heat exchanger, developed by VIVAQUA $\operatorname{scrl}^{\dagger}$ with heat exchange characteristics as shown in Table 1, was installed by VIVAQUA in 2013. It is placed at the spillway (into a storm water basin) of a general sewer into which both residential and commercial drains from the Municipality of Molenbeek, in the Brussels Capital Region, are collected. The heat exchanger at the spillway can be seen in Figure 2. The recovered heat is used to heat a single technical room, in which the control equipment for the storm water basin is placed. In light of the research project, the authors of this paper retrofitted the measuring equipment on this system at the end of 2014, in order to be able to quantify sewer temperatures and flows, and the potential heat recovery associated with the conditions at this site.

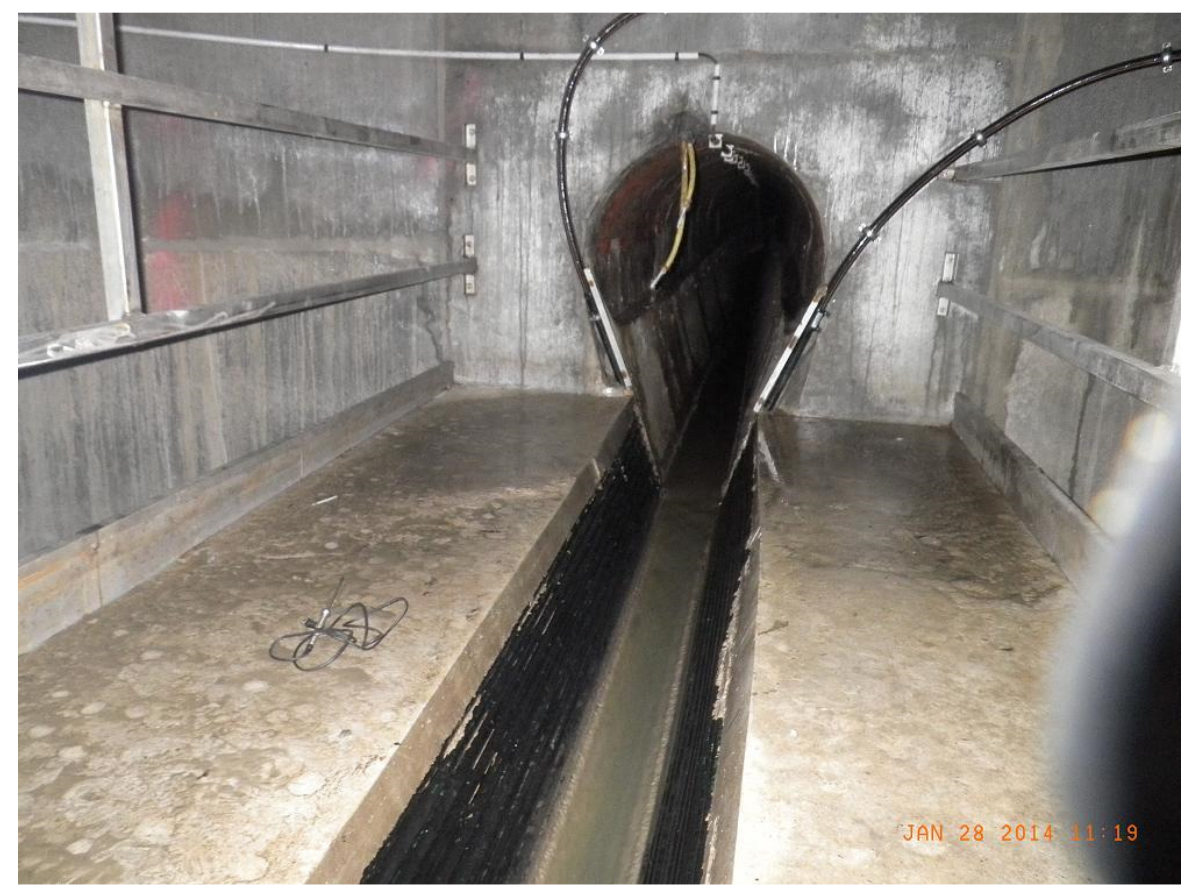

Figure 2. The heat exchanger at the MYRTES test facility

The heat exchanger is placed in an oval-shaped sewer section that is small $(80 / 140 \mathrm{~cm})$, compared to most of the sections in the sewer network in the Brussels

$\dagger$ VIVAQUA scrl is the managing entity for the sewer network in the Brussels Capital Region 
Capital Region. VIVAQUA scrl's underlying idea was to prove the feasibility in a small section, with a smaller flow and thus in unfavourable conditions. The line of thought was that if this feasibility is shown, the technique would be practicable in the majority of sewer sections in the region.

The idea of locating it at a spillway is one of convenience, as there is a platform available on which workers can stand. In this way the prototype could be installed without opening the street and interrupting traffic. The heat exchanger can be installed in sewer sections when these are opened for repair or replacement. It would replace a glass-reinforced polyester plate, which is installed nowadays in order to create a smoother surface, and reduce material deposition.

\section{OBSERVATIONS}

The information concerning wastewater temperatures in the Brussels Capital Region was not available at the start of this research project (May 2015). The first order of business was thus to quantify the wastewater temperature at the MYRTES test facility, and analyse its evolution over a day. The wastewater temperature has been monitored on the test site, starting from mid-December 2014, until the beginning of April 2015, and showing a wastewater temperature between 8 and $16{ }^{\circ} \mathrm{C}$ (Figure 3). It can be expected that these temperatures will run up even higher during the summer.

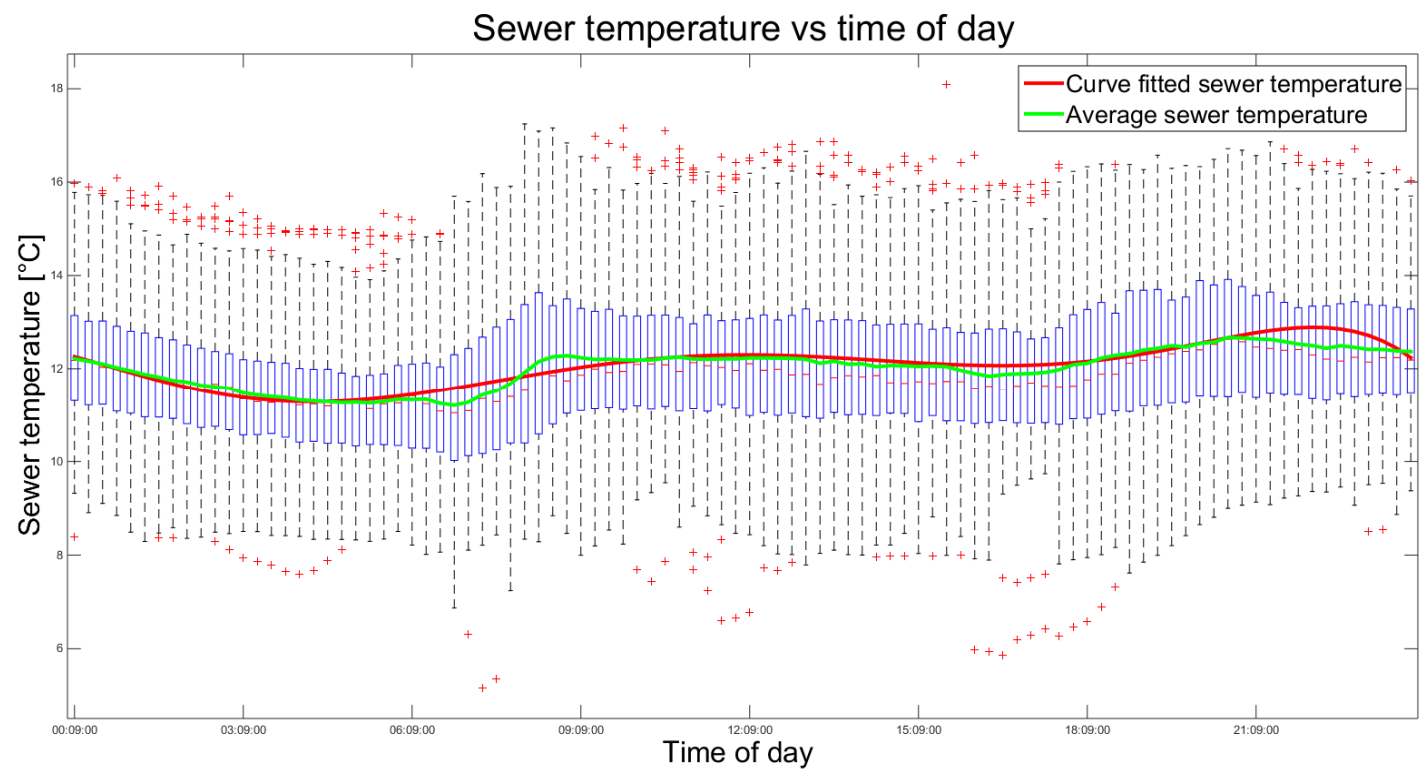

Figure 3. Evolution of the observed sewer temperature over a day

Figure 3 shows a boxplot of the measured wastewater temperatures, the blue box showing the interval of the $25^{\text {th }}$ to $75^{\text {th }}$ percentile values. Within the whiskers shown on the plot one can find $99.3 \%$ of the observed values. The average value (in green), and a polynomial curvefit (in red) are also shown in this figure.

Generally a fairly stable wastewater temperature is observed, with small but distinguishable increases in the morning (around $9 \mathrm{AM}$ ) and in the evening (around $8 \mathrm{PM}$ ). However, large rainfall or melting snow causes decreases of up to $2-3^{\circ} \mathrm{C}$ in the temperature of the wastewater, as can be seen in Figure 4, where important rainfall occurred between 6 and $8 \mathrm{AM}$. The wastewater flow at the location of the test facility is rather low compared to other locations in the sewer network, causing this effect to be more important at the test facility than in most other locations on the sewer network. However accounting for the influence of rainfall is an important factor to accurately predict potential heat recovery. 


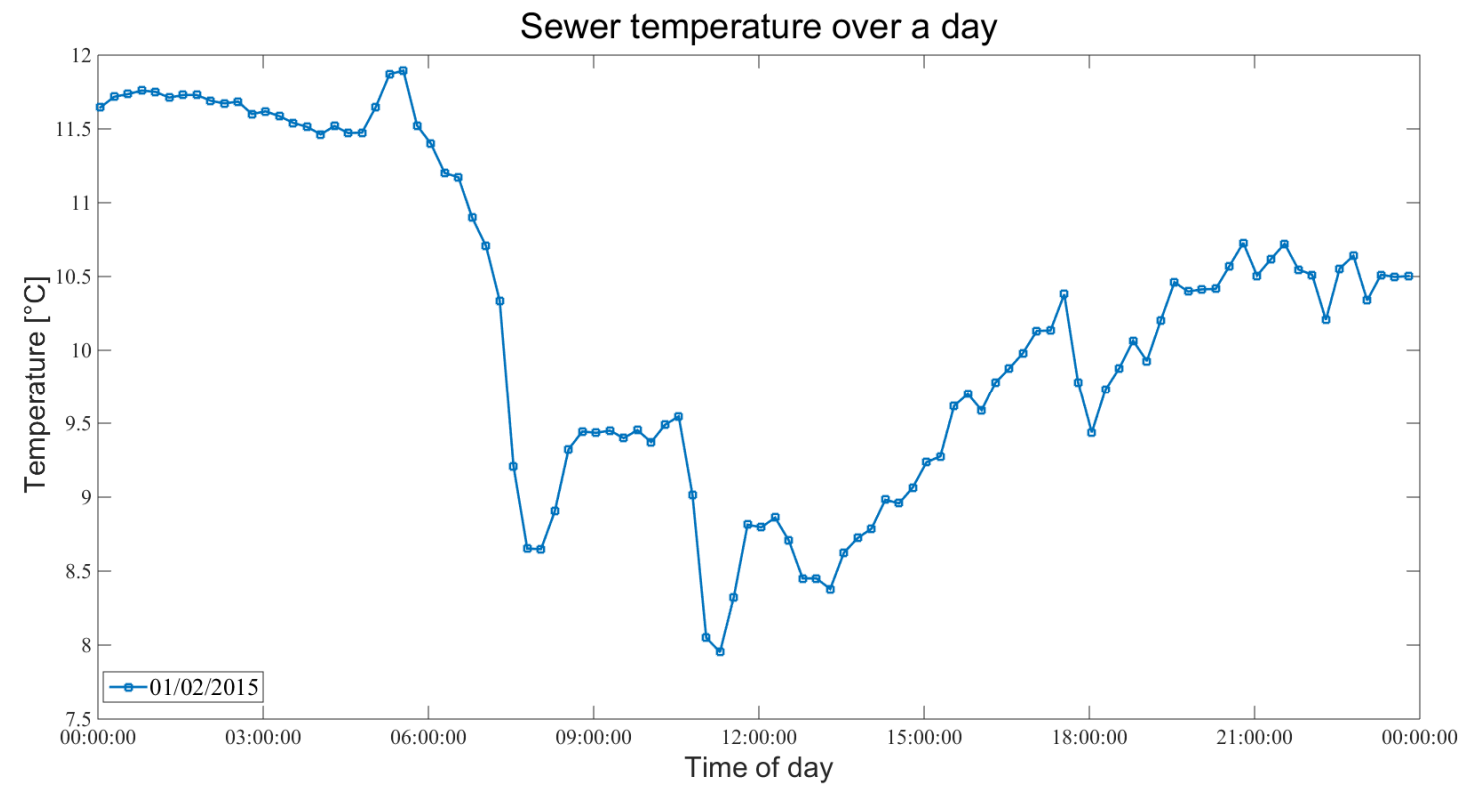

Figure 4. Example of the decrease in temperature due to rainfall

The flow accompanying these temperatures varies between $5-60 \mathrm{~m}^{3} / \mathrm{h}$. Considering the geometry of the sewer at the test facility, this corresponds to a height of the wastewater between $10-30 \mathrm{~cm}$. Similar to the observations of the wastewater temperature, a notable increase occurs in the morning. However, the daily variation is quite large, and heavily influenced by rain. The boxplot of the observed sewer flow is shown in Figure 5.

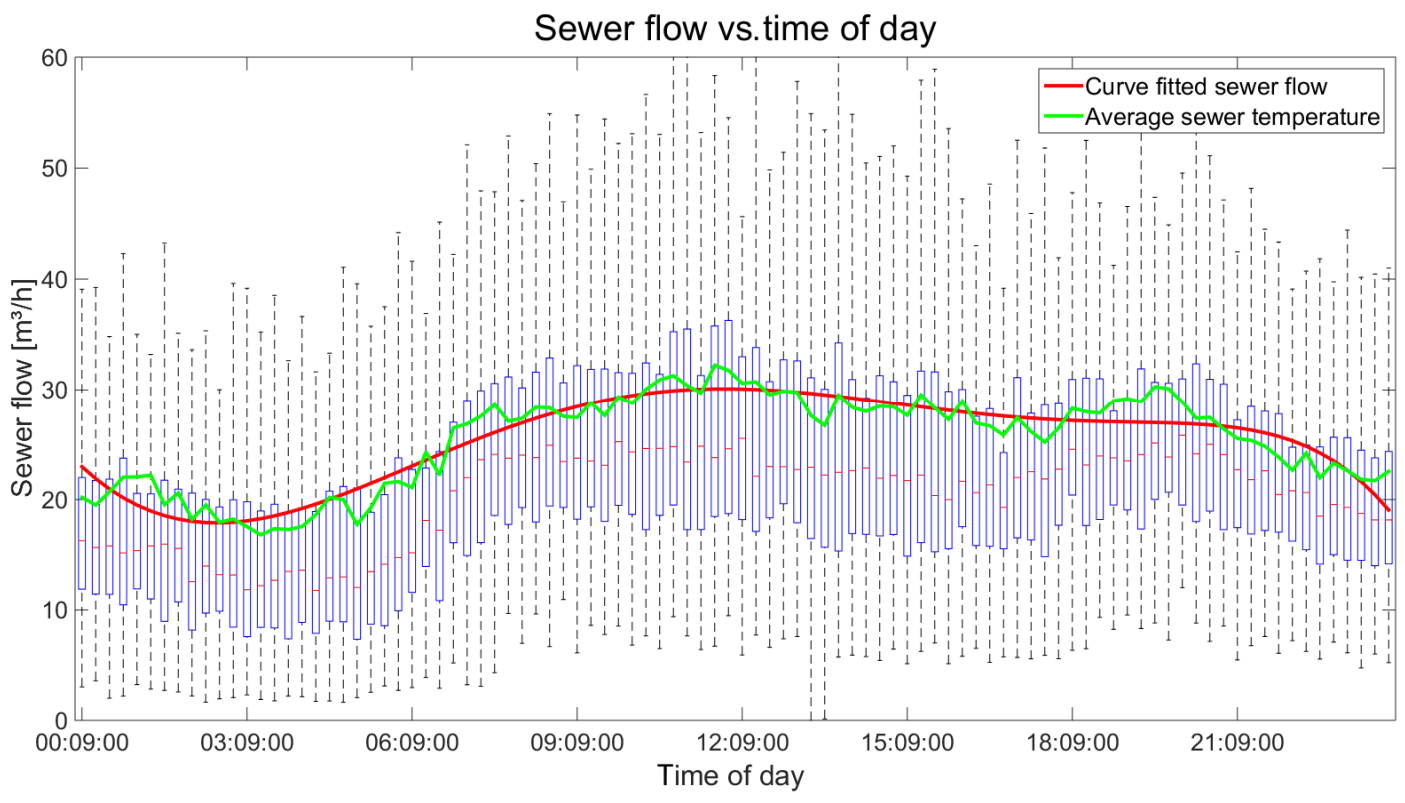

Figure 5. Evolution of the observed sewer volumetric flow over a day

Under these conditions for the wastewater temperature and flow, a recovered heating power lying between 2.5-5.5 $\mathrm{kW}$ (Figure 6) has been observed. This results in an observed space heating varying between $3.2-7 \mathrm{~kW}$, delivered by the heat pump, given the observed values for the Coefficient of Performance (COP) of this heat pump (3.7-5). The observed daily heating energy that is recovered lies between $30-55 \mathrm{kWh}$. The daily recovered heating energy is lower than expected, due to the capacity factor in eq. (1) of the heat pump: 


$$
\text { Capacity factor }=\frac{\text { Observed functioning time }}{\text { Maximum functioning time }}
$$

At the facility, the heat pumps capacity factor reached a value of around $50 \%$. This is partially due to inadequate sizing of certain system components such as tube size, distance between the heat exchanger and the heat pump, etc., and can be improved significantly given a more in-depth analysis of the situation at future installation sites, prior to the actual installation. In order to estimate the potential heat recovery, and available space heating power and energy, a model is used to predict potential heat recovery.

\section{Exchanged heat vs. Sewer temperature \& Height}

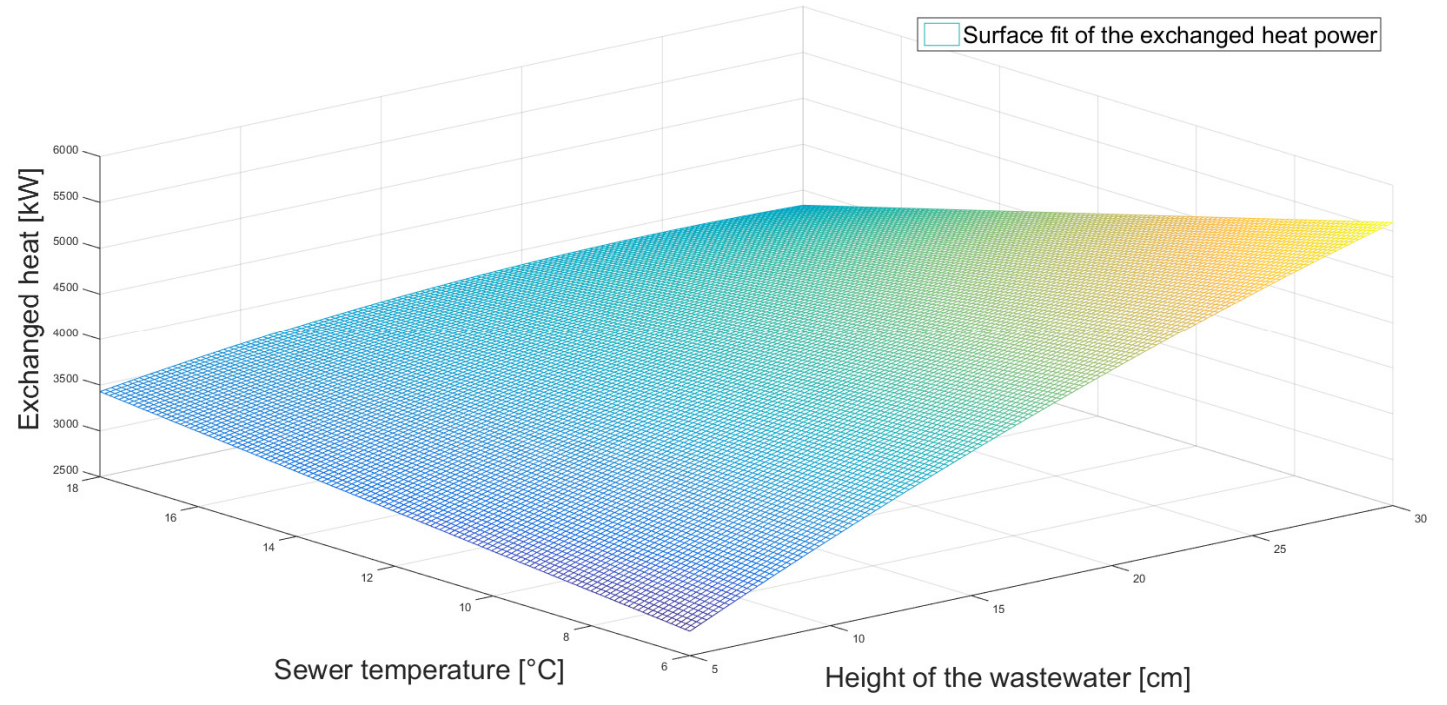

Figure 6. Exchanged heat vs temperature and sewer height

Figure 6 shows the surface fit of the experimental observations regarding the recovered heat with respect to the observed wastewater temperature and height (which is closely related to the wastewater flow). The height is considered here because it indicates the submergence of the tubes of the heat exchanger, which actually recover the heat from the wastewater. The surface fit is plotted a certain value range $(5-30 \mathrm{~cm}$ of height, 6-20 ${ }^{\circ} \mathrm{C}$ ), which contains the interval of observed values. In this figure one can observe that the recovered heat at maximum height and temperature is lower than the one at the same height and a smaller temperature. This is contradictory to what the theory predicts. This could be (partially) explained by the fact that high temperature and a large height generally don't occur at the same time, and that the influence of outliers and measuring errors is therefore greater. Large rainfall causes the water level to rise, but this also reduces the sewer temperature (Figure 4), explaining the low occurrence rate of simultaneously high temperatures and large water levels.

Here one can observe that a larger wastewater flow, and thus a greater height, has a larger influence on the recovered heat than the wastewater temperature. When selecting appropriate sites for the installation of wastewater heat recovery systems, it could be more advantageous to select a site where wastewater temperatures are lower, but where the wastewater flow is more important.

\section{METHODS \& MODEL}

This section describes the employed method, the structure of the model, and the governing equations in the model. 


\section{Monte Carlo method}

The distribution of the observed sewer temperature, sewer flow and ambient temperature is used in a Monte Carlo simulation, where the recoverable heat from the wastewater is simulated, but also the performance of the heat pump, based on the data sheet of the Stiebel-Eltron WPF 5. This simulation is performed for the values observed at 15 minute intervals, as is the case for the measurements. The output values are then employed to calculate a simplified Levelised Cost Of Energy (LCOE) and a simplified Total Equivalent Warming Impact (TEWI). The general structure of this Monte Carlo method is given in Figure 7.

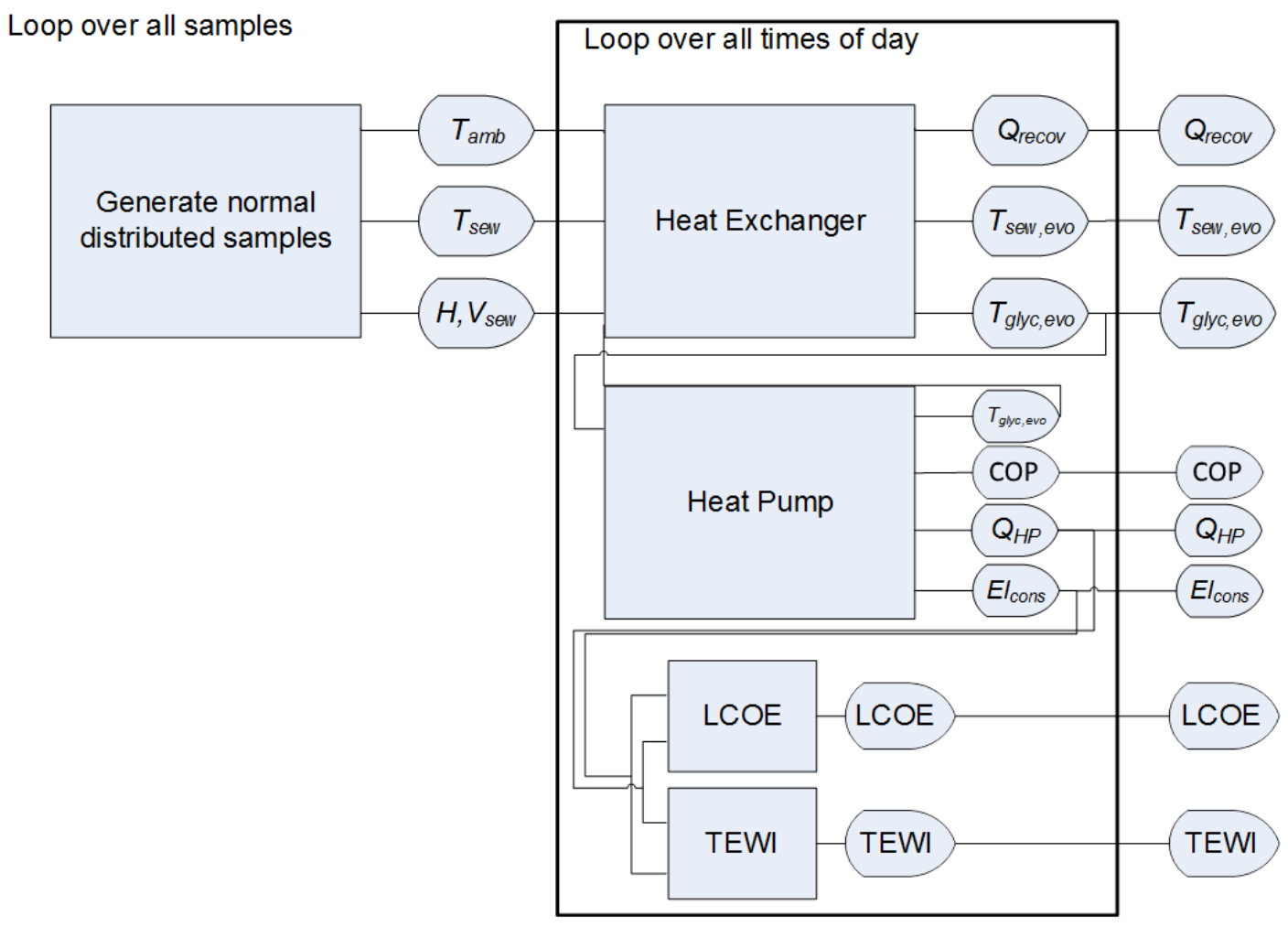

Figure 7. General structure of the Monte Carlo method

In order to estimate the competitiveness of these types of systems with traditional gas boilers, a simplified LCOE, considering the costs for a household consumer (and not the installation of the heat exchanger, as is explained further), and TEWI are compared with those of traditional gas boiler systems, and with traditional air heat pumps, considering the local conditions at the MYRTES test facility.

\section{Heat recovery model}

The heat recovery model consists of two parts. Firstly it estimates the heat that can be recovered from the sewer flow, using the heat exchanger described earlier. Subsequently the temperature increase of the primary working fluid of the heat pump, which is obtained from this recovered heat, is calculated. The higher temperature of this working fluid results in a higher value for the COP of the heat pump, which is calculated in the model of the heat pump. Using this model one can then calculate the heat that is available for space heating. The main components of this model are described below.

Heat exchanger. The observations, described above, have been used to validate a model that quantifies the recoverable heat in the heat exchanger. The assumptions used in the model are the following: 
- The heat exchange by radiation is negligible compared to the heat exchange by conduction and convection;

- Fouling, or the deposition of material, of the heat exchanger is not taken into account;

- Ambient and wastewater temperatures are considered to be uniform, over their respective volume sections;

- Transient behaviour is neglected; the model considers steady-state functioning modes.

The model considers both the heat recovery by flow through the immersed and the non-immers tubes of the heat exchanger, and estimates the recovered heat, but also the temperature evolution of the waste water and the temperature evolution of the primary working fluid of the heat pump, as can be seen in Figure 8.

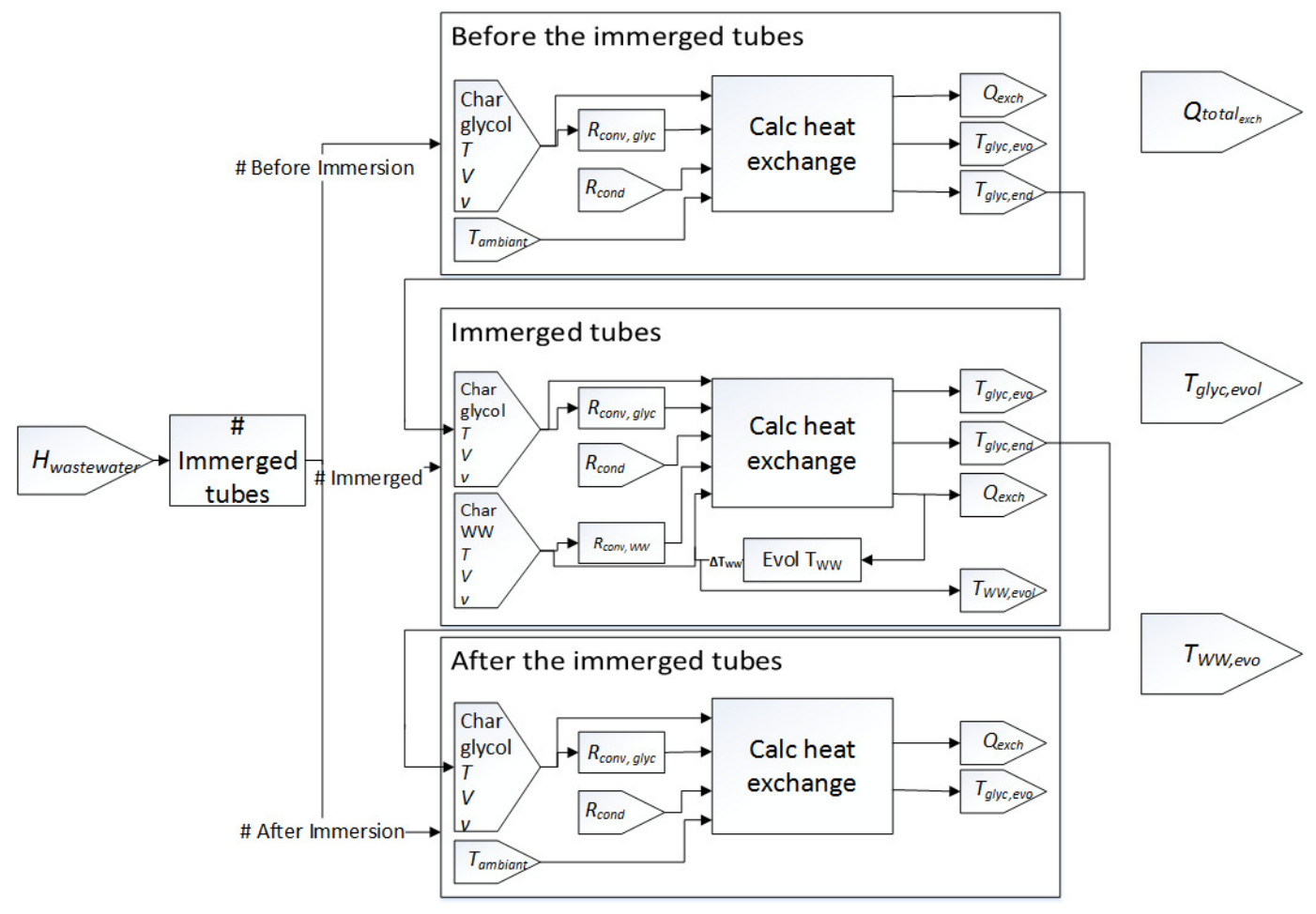

Figure 8. Principal scheme of the heat exchanger model

The exchanged heat is calculated using the material properties of the heat exchanger, and the characteristics of the flow of the wastewater and the primary fluid, as described in eq. (2):

$$
\dot{Q}_{\mathrm{HE}}=\frac{\Delta T}{R_{\mathrm{total}}}
$$

In this equation the total resistance to heat exchange is given by the sum of the resistance to heat exchange by convection and conduction, as is shown in eq. (3):

$$
R_{\mathrm{total}}=\frac{t}{K_{\mathrm{PEHD}} A}+\frac{1}{h_{\mathrm{WW}} A}+\frac{1}{h_{\mathrm{PF}} A}
$$

The exchanged heat can then be used to calculate the decrease in temperature of the wastewater, and the increase in temperature of the primary fluid of the heat pump. This is 
shown in eq. (4), the outlet temperature of the heat exchanger is then used as the inlet temperature of the heat pump, as is explained further:

$$
\dot{Q}_{\mathrm{HE}}=\dot{m}_{\mathrm{WW}} C_{p, \mathrm{WW}}\left(T_{\mathrm{WW}, \text { in }}-T_{\mathrm{WW}, \text { out }}\right)=\dot{m}_{\mathrm{PF}} C_{p, \mathrm{PF}}\left(T_{\mathrm{PF}, \text { in }}-T_{\mathrm{PF}, \text { out }}\right)
$$

The observed results, described in the previous section (from January $20^{\text {th }}$ till April $8^{\text {th }}$ ) have been used to validate the model. Outside of these dates, the information was either not available or outside temperatures were too high and heating was not required.

Heat pump. The performance, and more particularly the COP in eq. (5) of the heat pump are highly dependent on the inlet temperature of the primary fluid in the condenser of the heat pump. The higher this temperature, the higher the value of the COP, and thus of the utilizable output heat ( $Q_{\text {out }}$ ) for each unit of applied compressor work $\left(W_{\text {in }}\right)$. This dependency is specific to each heat pump model, in the case discussed in this paper, the 'Stiebel-Eltron WPF 5' heat pump is used, and the performance data can be found in its data sheet:

$$
\mathrm{COP}=\frac{Q_{\text {out }}}{W_{\text {in }}}=\frac{Q_{\text {in }}+W_{\text {in }}}{W_{\text {in }}}
$$

This allows us not only to estimate the available heating power, and the consumed compressor work, but also to retrace the evolution of the primary fluid's temperature in eq. (4). In these models, it is assumed that the heat pump is operated over a certain number of equivalent heating days, in order to feed the heat required for the buffer (Figure 1). It is considered that the heat pump functions a certain number of days, at full operation ( $24 \mathrm{~h}$, and full power). For individual households the value of the equivalent heating days varies from 60 to 150 . The profitability of these systems is expected to increase with increased heat consumption, in order to observe this behaviour these values are also compared with constant operation over a full year (365 equivalent heating days). This represents a similar sized system that is used as input for a heating network, operating year round.

\section{Financial model}

Based on the results from the heat recovery model, a financial model is used to estimate the competitiveness of this technology. In this case the LCOE method is used, comparing the LCOE for the consumer with the LCOE of a traditional gas boiler system, or a classical air source heat pump. The method and employed parameters are described in this section.

The simplified LCOE is calculated using eq. (6) [24], where the investment cost is considered to be the price of the heat pump or gas boiler. General employed values are given in Table 2. Because electricity and gas prices vary over time, but also in between different providers at different locations, the LCOE is calculated with different electricity and gas prices, ranging from the lowest Belgian price, to the most expensive one [25]:

$$
\text { LCOE }=\frac{\sum_{n=1}^{\text {lifetime }} \frac{I_{n}+M_{n}+F_{n}}{(1+r)^{n}}}{\sum_{n=1}^{\text {lifetime }} \frac{E_{n}}{(1+r)^{n}}}
$$

The cost of installing the heat exchanger is not considered in the LCOE calculation, as the heat exchanger would replace a glass reinforced polyester plate, and the estimated 
costs are similar. The capital investment is considered to be the cost price of the device. In order to compare the LCOE of the heat recovery system to the one of a classical heating system, the LCOE and TEWI are also calculated for a VITOPEND $100 \mathrm{~W}$ gas boiler, and for a 'DAIKIN ALTHERMA' heat air pump. The different devices and their parameters are described in Table 3.

Table 2. Values for the LCOE calculation

\begin{tabular}{c|c|c}
\hline Investment cost & $I_{1}$ & Price of the device \\
Maintenance cost & $M_{n}$ & $0.02 I_{1}$ \\
Fuel cost & $F_{n}$ & $E_{n} E l_{\text {price }}$ \\
Electricity price [25] & $E l_{\text {price }}$ & $0.12-0.18-0.23 \mathrm{EUR} / \mathrm{kWh}$ \\
Gas price & & $0.03-0.05-0.07 \mathrm{EUR} / \mathrm{kWh}$ \\
Yearly produced heat & $E_{n}$ & Result of the simulation \\
Discount rate [26] & $r$ & 0.03 \\
\hline
\end{tabular}

Table 3. Values for the LCOE calculation

\begin{tabular}{cc}
\hline \multicolumn{2}{c}{ Water source heat pump } \\
\hline Type & Stiebel-Eltron WPF 5 \\
Rated power & $5 \mathrm{~kW}$ \\
Price & EUR 7,800 \\
Refrigerant & $1.6 \mathrm{~kg}$ \\
Mass of refrigerant & Air source heat pump \\
\hline Type & Daikin Altherma EV LQ - CV3 \\
Rated power & $5.12 \mathrm{~kW}$ \\
Price & EUR 5,360 \\
Refrigerant & R410a \\
Mass of refrigerant & $1.45 \mathrm{~kg}$ \\
\hline \\
\hline Type \\
Rated power & Gas boiler \\
Price & Vitopend 100-W \\
& $10.7 \mathrm{~kW}$ \\
& EUR 2,500
\end{tabular}

\section{Environmental model}

In order to estimate the environmental impact of the three discussed heating systems, the Total Equivalent Warming Impact (TEWI), divided by the produced heat is considered.

The simplified TEWI, is based on the emissions related to the functioning of the heating devices, the emissions related to construction and decomposition of these devices are considered to be negligible, compared to the emissions related to the fuel [27]. The formula for heat pumps is given in eq. (7) and other employed values are given in Table 4:

$$
\mathrm{TEWI}=\mathrm{GWP}_{\text {refr }} L n+\mathrm{GWP}_{\text {refr }} m_{\text {refr }}\left(1-\alpha_{\text {recov }}\right)+E_{\text {cons }} K_{\mathrm{el}} n \mathrm{HD}
$$

Similarly for the gas boiler system the formula is given by eq. (8):

$$
\mathrm{TEWI}_{\text {gas }}=\operatorname{Gas}_{\text {conso }} K_{\text {gas }} n \mathrm{HD}
$$

\footnotetext{
$¥ 600 \mathrm{EUR} / \mathrm{m}$ as affirmed by the Brussels sewer manager VIVAQUA
} 
Table 4. Values for the TEWI calculation

\begin{tabular}{c|c|c}
\hline Global warming potential for R410a & $\mathrm{GWP}_{\text {refr }}$ & $1,980 \mathrm{~kg} \mathrm{CO} 2 / \mathrm{kg}_{\mathrm{refr}}$ \\
Refrigerant leakage rate & $L$ & $0.02 \mathrm{~kg} / \mathrm{yr}$ \\
Lifetime & $n$ & 20 years \\
Recoverable refrigerant & $\alpha_{\text {recov }}$ & 0.8 \\
$\mathrm{CO}_{2}$ intensity of electricity [24] & $K_{\mathrm{el}}$ & $617 \mathrm{~g} \mathrm{CO}_{2} / \mathrm{kWh}$ \\
$\mathrm{CO}_{2}$ intensity of gas [24] & $K_{\text {gas }}$ & $277 \mathrm{~g} \mathrm{CO}_{2} / \mathrm{kWh}$ \\
\hline
\end{tabular}

\section{SIMULATION RESULTS AND DISCUSSION}

This section discusses the results of the simulations through the different models, as described in the previous section.

\section{Results of the heat recovery model}

It has been observed that, at the test facility, the heat recovery system is not exploiting its full potential. In order to estimate the full available potential, the system operation has been simulated in normal operating conditions, considering adequate sizing of all components.

The statistical analysis of the heat that can be recovered from the sewer and the available heat for space heating are shown in Figures 9 and 10. The required outlet temperature for sanitary hot water is $60{ }^{\circ} \mathrm{C}$, in order to avoid the formation of Legionella Pneumophila [28], The WPF 5 heat pump used at this installation site is not able to reach these temperatures, therefore only the space heating case, at $45^{\circ} \mathrm{C}$ is considered in this analysis.

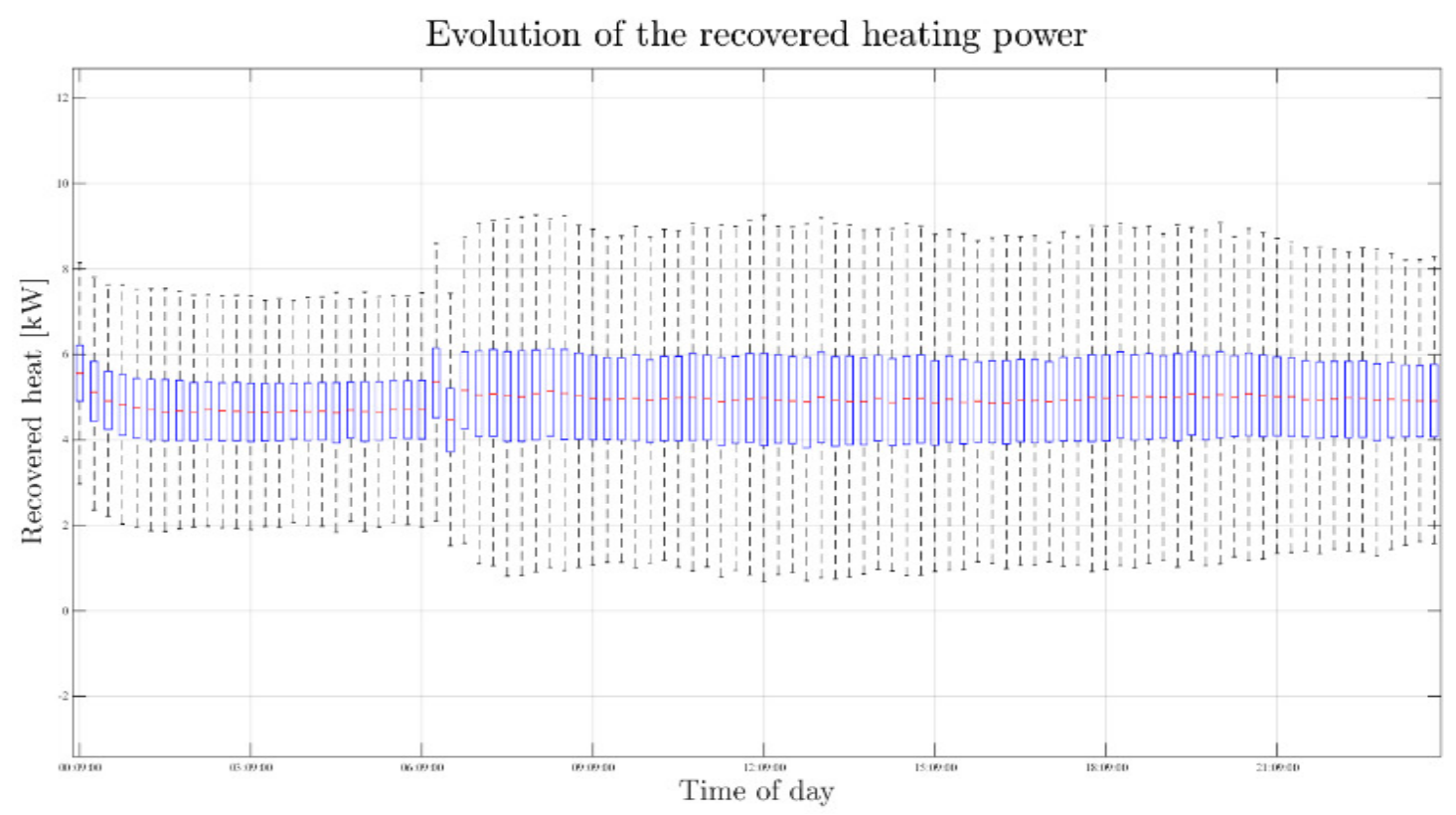

Figure 9. Evolution of the heat recovery potential in the sewer

One can observe that the $99.3 \%$ interval shows a minimum value of the available heating power of around $6.3 \mathrm{~kW}$ (Figure 10). The available and recovered energy are shown in Table 5.

The simulated COP is around 3.5 over the entire day, which is slightly lower than the one that is actually observed at the test site. The simulations show that the outlet temperature of the glycolated water from the heat pump exceeds its $4-8{ }^{\circ} \mathrm{C}$ working 
interval just under $5 \%$ of the time, which might account for some of the down time of the heat pump. The simulated sewer temperature after the heat exchanger is lower than $10^{\circ} \mathrm{C}$ in around $9 \%$ of the cases. In the case of a single heat exchanger this does not cause any problems, as the temperature increases with further inflow of wastewater. However, in case of a large number of exchangers this might influence the bacterial activity in the water cleansing process, specifically in the nitrification process [29]. The effect of placing these types of heat exchanger over the entire network should therefore be investigated.

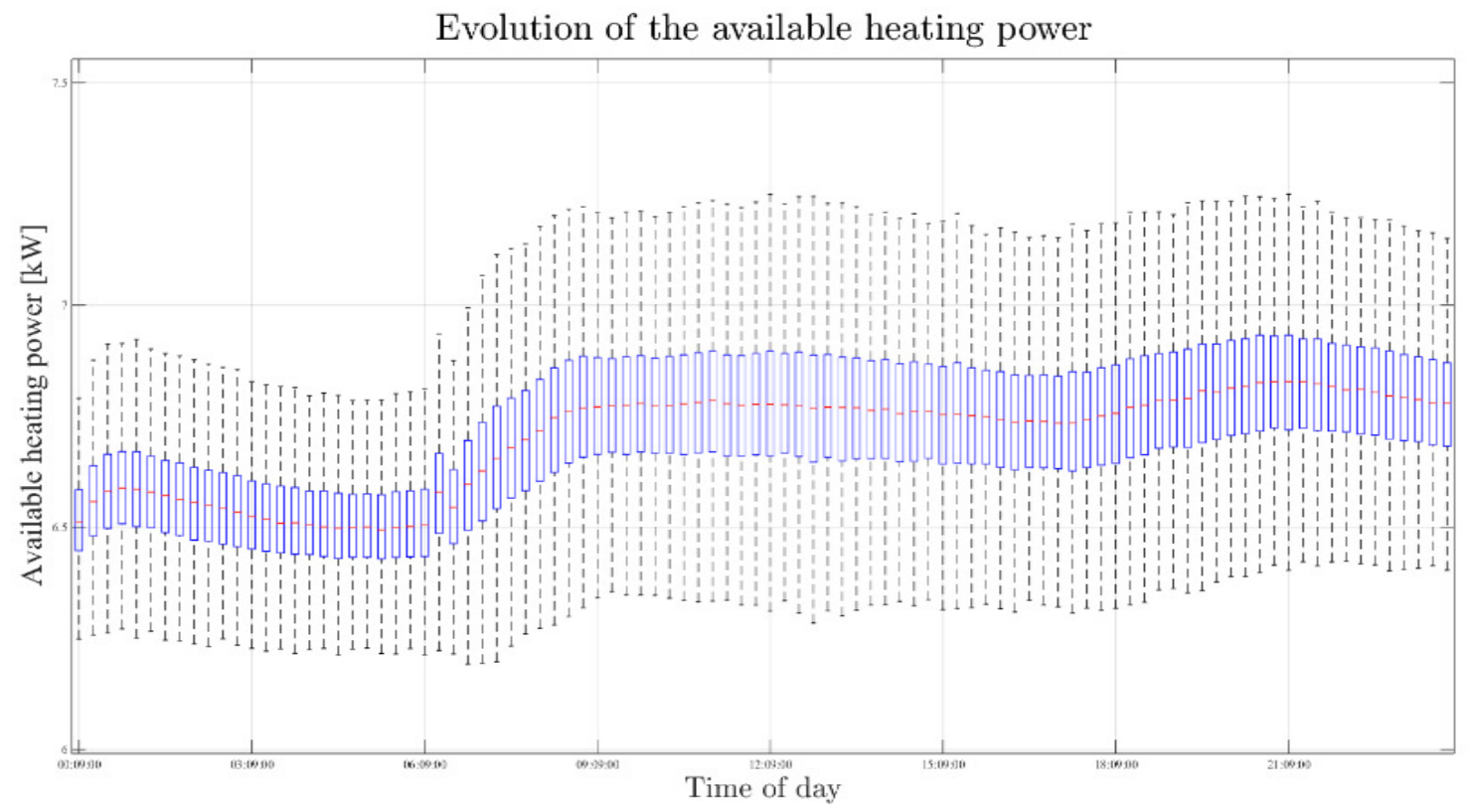

Figure 10. Evolution of the available space heating power

Table 5. Results of the Monte Carlo simulation

\begin{tabular}{ccc}
\hline & \multicolumn{2}{c}{ Heat recovery system } \\
\cline { 2 - 3 } & $\mu$ & $\sigma$ \\
\hline Recovered heat & $117.86 \mathrm{kWh}$ & $0.70 \mathrm{kWh}$ \\
Available heat & $160.85 \mathrm{kWh}$ & $0.59 \mathrm{kWh}$ \\
\hline
\end{tabular}

\section{Results of the financial model}

The values in Table 5 are then used to calculate the LCOE and TEWI, with different electricity and gas prices, and at different equivalent heating days. These equivalent heating days are obtained by dividing the total consumption by the maximum daily production from the wastewater heat recovery system (as given in Table 5). Hence this indicates the number of heating days, if the heat pump would, at any moment of these days, produce at its maximum level.

As can be seen in Figure 11, the LCOE is highly dependent on the electricity and gas tariffs. For an average household consumer in Brussels, an electricity price of around $18 \mathrm{cEUR} / \mathrm{kWh}$ and a gas price of $5 \mathrm{cEUR} / \mathrm{kWh}$ are applied. With these prices one can observe that the LCOE of the heat recovery system is higher than the one for the gas boiler system. For an individual consumer, the wastewater recovery system yields a more expensive heating solution than the traditional gas boiler system. It is however, cheaper than the air heat pump solution, mainly caused by an improved COP. The wastewater heat recovery system could be more profitable for an individual consumer on locations where a profitable electricity price is available, but where only an average gas price is available. One can also observe that given these prices, that the wastewater heat recovery 
systems are more competitive with increased heating consumption. A large year- round consumer, like, for example, a heat source for a heating network is more competitive with gas boiler systems. Therefore a strategy of collective heating, through heating networks or other arrangements, will prove to be financially more attractive for a consumer. Furthermore, a large, year-round electricity consumer such as a heat source for a heating network could benefit from more advantageous electricity prices.

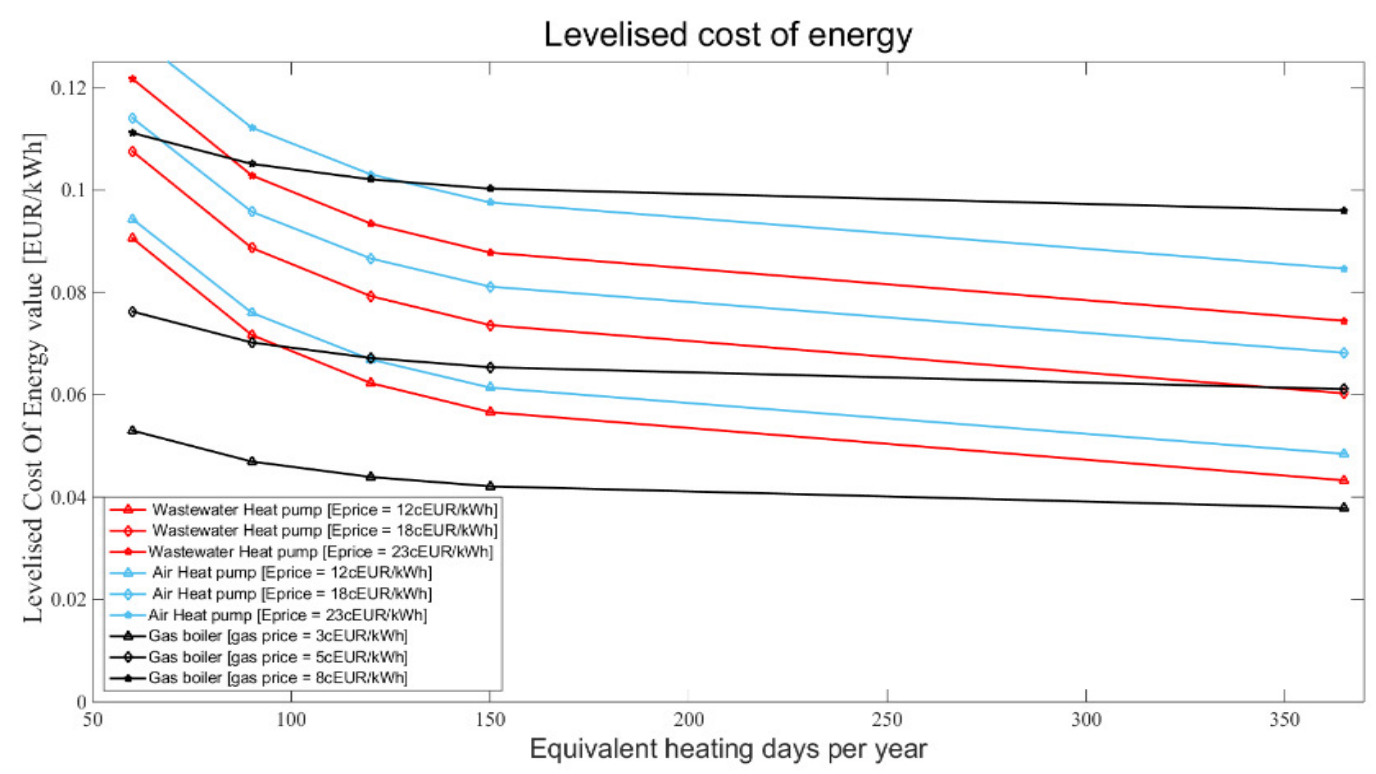

Figure 11. Levelised cost of energy at different heating days

\section{Results of the environmental model}

Figure 12 shows the simplified TEWI for both technologies. One can observe that the wastewater heat recovery system shows a reduction in equivalent $\mathrm{CO}_{2}$ emissions of around $49 \%$ over its lifetime of 20 years, compared to gas boilers. It also shows a reduction of around $13 \%$ in equivalent $\mathrm{CO}_{2}$ emissions compared to traditional air heat pumps. This could represent a significant reduction in greenhouse gas emissions in the Brussels Capital Region.

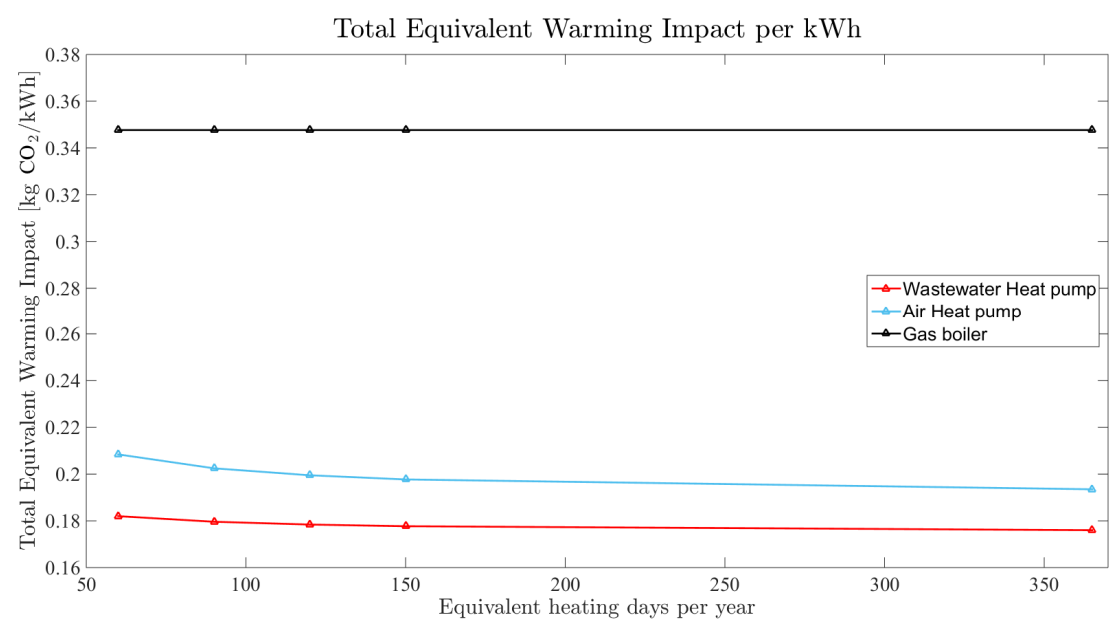

Figure 12. TEWI per produced $\mathrm{kWh}$ of heat

\section{Discussion}

At this test facility a $6 \mathrm{~m}$ long heat exchanger was installed, the initial hypothesis being to place a heat exchanger per home, as centralised heating systems are not common 
in the Brussels Capital Region. However in case of centralised heating systems and district heating, a larger heat exchanger could be necessary, as heating demand is greater as well. Dimensioning of heat exchangers plays a vital role in the development and eventually the deployment of these types of systems. Employing these wastewater heat recovery systems at larger power and energy consumers, such as heating networks, also increases their potential profitability and competitiveness, as can be seen in Figure 11.

The assumption that all produced heat is consumed is not realistic in individual homes without a thermal storage tank (buffer). This thermal storage is necessary in order to exploit the heating potential during periods when heat consumption is low. Another possibility is to use heat pumps in combination with district heating networks. Through the use of heat pumps on a large scale, sensible heat energy storage could be used to dampen production peaks of an increasingly intermittent energy production mix.

\section{IMPLICATIONS FOR THE BRUSSELS CAPITAL REGION}

In order to have an estimate of the amount of buildings that would be eligible to be heated with a wastewater heat recovery system, the surface that can be heated with this system is calculated, both for an average Brussels residence as for a 'EPB-conform' residence (a residence compliant with the norms regarding the Energetic Performance in Buildings). The heating energy consumption of an average Brussels residence is calculated using the statistics in [30]. The EPB directive was introduced in Brussels' legislation in 2002. In its actual (2016) form it states that the maximum yearly heating energy consumption is $15 \mathrm{kWh} /\left(\mathrm{m}^{2}\right.$ year $)$. The power consumption of both the average residence and a 'EPB-conform' residence, as expressed in [28], are shown in Table 6, as are their yearly heat consumptions.

Table 6. Required heat and heating power for different types of residencies

\begin{tabular}{ccc}
\hline & Average in Brussels & 'EPB-conform' \\
\hline Heat consumption & $175.46 \mathrm{kWh} /\left(\mathrm{m}^{2}\right.$ year $)$ & $15 \mathrm{kWh} /\left(\mathrm{m}^{2}\right.$ year $)$ \\
Required heating power & $100 \mathrm{~W} / \mathrm{m}^{2}$ & $10 \mathrm{~W} / \mathrm{m}^{2}$ \\
\hline
\end{tabular}

In order to estimate the surface that can be heated by the wastewater heat recovery system, one must now determine whether the power or the heating energy is the delimiting factor for the surface. The heating energy consumption can't be estimated directly from the values of Table 6, as the heating energy will not be consumed during summer time for example. Thus, to estimate the daily required heating energy per square meter, Heating Degree Days (HDD) [31] are employed. Using the observation for the HDD (in the period 2006-2015), and the observed outside temperatures in Brussels [32], a value of 90 equivalent heating days (see earlier) is used. This value is conservative in the sense that, the lower this value, the larger the required heat is, and thus a lower value for the heatable surface is obtained.

The estimation for the surface that can be heated by the wastewater heat recovery system, taking into account two possible delimiting factors, for both the average Brussels residence as for the 'EPB-compliant' residence are given in Table 7.

Table 7. Maximal heat-able surface for different delimiting factors

\begin{tabular}{ccc}
\hline Delimiting factor & Average in Brussels & 'EPB-compliant' \\
\hline Heat consumption & $81.79 \mathrm{~m}^{2}$ & $956.70 \mathrm{~m}^{2}$ \\
Required heating power & $63 \mathrm{~m}^{2}$ & $630 \mathrm{~m}^{2}$ \\
\hline
\end{tabular}


Given the following assumptions:

- All residences built before 2011 are average residences;

- All residences built after 2011 are 'PEB-compliant';

- The growth rate of the number of residences for the period 2011-2016 is the same as described in [30];

- The distribution of the surface of the different residences in the Brussels Capital region remains the same as described in [30].

An estimate maximum 35\% of residences in the Brussels Capital Regioncould be heated using these systems. However one still has to take into account that the sewer water temperature should not drop below $10{ }^{\circ} \mathrm{C}$, and that not all of these buildings have access to the sewage system to recover its heat. Furthermore, when these buildings lie geographically close to each other, sewer temperature might be lower due to previous heat outtakes, and thus the available heat might be lower. The real number of residences that can be heated will be significantly lower.

This study focuses on the implementation of heat recovery systems in existing sewer systems, in the urban area of the Brussels Capital Region. Heat recovery systems, using a similar topology can also be installed in rural areas, however the characteristics of the wastewater flow (temperature, mass flow) are expected to be significantly different. The dimensioning of systems in rural areas will thus differ from the ones in urban areas. Moreover, installing these systems in newly built sewers allows for adequate dimensioning of the sewer, and adapted design of the sewer system, which could lead to improved efficiency and lower costs.

\section{CONCLUSIONS AND PERSPECTIVES}

In light of further improving the efficiency of the wastewater cycle and reducing the energy consumption of buildings, recovering heat from wastewater is a pathway that should be investigated. It is already employed in several cities in Europe, where its feasibility and efficiency have already been proven. However existing projects all focus on newly constructed sewer systems, whereas this research focuses on implementing these techniques in the renovation of existing sewer systems.

The test facility installed in the sewer network of the Brussels Capital Region shows sewer temperatures between $8-16{ }^{\circ} \mathrm{C}$ in winter, and wastewater flows varying between $5-60 \mathrm{~m}^{3} / \mathrm{h}$. These flow conditions result in a recovery of heat of up to $5.5 \mathrm{~kW}$. The observations also indicate that, when selecting appropriate sites for installing these types of systems, the flow of the wastewater is a parameter with larger importance than the wastewater temperature. One important parameter to be monitored is the decrease in wastewater temperature due to this heat recovery, as it has an adverse effect on the nitrification process in wastewater treatment plants.

Tests at the installed test facility show a heating energy recovery up to $55 \mathrm{kWh}$ per day, despite the fact that working conditions are far from ideal. With improvements in these working conditions potentially up to $115 \mathrm{kWh}$ per day could be recovered, resulting in a space heating energy of around $160 \mathrm{kWh}$. The available heating power, at the outlet of the heat pump has an estimated minimal value of $6.3 \mathrm{~kW}$. This results in a heatable surface of $63 \mathrm{~m}^{2}$, for an average Brussels home, and around $630 \mathrm{~m}^{2}$ for a 'PEB-compliant', passive residence. Given some assumptions mentioned earlier, a maximum of $35 \%$ of Brussels residences, existing in 2016, are eligible for these individual wastewater heat recovery systems. However this number will be strongly reduced due to geographical proximity between potential sites, and difficulties with the access to the sewer network. Each case should be assessed individually, given its specific parameters. 
Heat recovery at this test facility shows a potential to deliver (a part of) the heating energy required to heat an average Brussels household, however back-up systems remain necessary, to provide for, amongst others, the sanitary hot water consumption peaks, because the described system is not able to reach a sufficiently high temperature to heat sanitary hot water. There is no information available on general wastewater temperatures and flows in the Brussels Capital Region, and the reproducibility of the results from this test facility remains to be investigated. Another important factor to be investigated is the exploitation strategy: will the development of these types of systems be used in philosophy of single-home heating, or will it benefit the development of centralized heating systems?

Simulations show that a financial benefit is within reach, when the system is used year-round, at its maximum capacity, which could be the case when used in combination with heating networks. The potential for profitability increases with the consumed heat. However, at actual gas and electricity prices in the Brussels Capital region, the financial benefit, compared to gas boilers, for a single household consumer is only achievable when a favourable electricity price is in effect, and a favourable gas price is not obtainable. The wastewater heat recovery system is cheaper than a traditional air heat pump, related to an increased COP. Simulations also showed a reduction of the environmental impact related to greenhouse gas emissions of up to $49 \%$ compared to gas boiler systems, and up to $13 \%$ compared to classical air heat pumps. These results are obtained through TEWI calculations.

In future work the evolution of available space heating power should be compared to load profiles. In these simulations one type of heat pump and gas boiler are compared. In order to make general conclusions a statistical analysis of multiple types of heat pumps and gas boilers should be made.

The implementation of these systems on a larger scale, for example in large collectors of wastewater treatment plants, and their implementation in heating networks should be investigated. Also the financial and legal aspects of the remuneration mechanisms for the sewer network managers should be investigated.

\section{ACKNOWLEDGEMENT}

This research is performed under the sponsorship of, and in close collaboration with VIVAQUA scrl. Our thanks go to ir. Serge De Ridder, Julien Fernandez Mena and Célestin Kankonde, members of the VIVAQUA organization.

\section{NOMENCLATURE}

A

$C_{p}$

$D N$

E

$E l_{\text {price }}$

F

GWP

$h$

I

$k$

$K_{\mathrm{el}}$

$K_{\text {gas }}$

$L$

LCOE heat exchange surface

specific heat capacity

nominal diameter

produced/recovered energy

electricity price

fuel cost

global warming potential

convective heat transfer coefficient

investment cost

thermal conductivity

$\mathrm{CO}_{2}$ intensity of electricity

$\mathrm{CO}_{2}$ intensity of gas

leakage rate

levelized cost of energy

\author{
$\left[\mathrm{m}^{2}\right]$ \\ [J/kgK] \\ [mm] \\ [kWh] \\ [EUR/kWh] \\ [EUR] \\ $\left[\mathrm{kg} \mathrm{CO}_{2} / \mathrm{kg}_{\text {refr }}\right]$ \\ $\left[\mathrm{W} / \mathrm{m}^{2} \mathrm{~K}\right]$ \\ [EUR] \\ $[\mathrm{W} / \mathrm{mK}]$ \\ [ $\left.\mathrm{kg} \mathrm{CO}_{2} / \mathrm{kWh}\right]$ \\ [ $\left.\mathrm{kg} \mathrm{CO}_{2} / \mathrm{kWh}\right]$ \\ [-] \\ [EUR/kWh]
}




\begin{tabular}{ll}
\hline$m$ & mass \\
$\dot{m}$ & mass flow \\
$M$ & maintenance cost \\
$r$ & discount rate \\
$R_{\text {total }}$ & total thermal resistance \\
$\dot{Q}$ & heat flow \\
$t$ & thickness of the pipe \\
$W$ & work \\
Subscript & \\
HE & \\
WW & heat exchanger \\
PF & wastewater \\
in & primary fluid of the heat pump \\
out & into the heat pump \\
refr & out of the heat pump \\
& refrigerant
\end{tabular}

\section{Greek letters}

$\begin{array}{lll}\alpha_{\text {recov }} & \text { recovery rate } & {[-]} \\ \mu & \text { average value } & {[-]} \\ \sigma & \text { standard deviation } & {[-]}\end{array}$

\begin{tabular}{ll}
\multicolumn{2}{c}{ Abbreviations } \\
COP & Coefficient of Performance \\
MEG & Mono-Ethylene Glycol \\
PEHD & Poly-Ethylene of High Denisty \\
EPB & Energy Performance in Buildings \\
HDD & Heating Degree Days \\
HD & Equivalent Heating Days
\end{tabular}

[kg]

$[\mathrm{kg} / \mathrm{s}]$

[EUR]

[\%]

$[\mathrm{K} / \mathrm{W}]$

[W]

[mm]

[W]

\section{REFERENCES}

1. Environmental Change Institute, Country Pictures: Belgium, 2000.

2. Schmid, F., Sewage Water: Interesting Heat Source for Heat Pumps and Chillers, $9^{\text {th }}$ International IEA Heat Pump Conference, Vol. 1, pp 1-12, 2008.

3. Vieira, A. S., Humphrys, S., Stewart, R. and Beal, C., Optimising Residential Water Heating System Performance to Minimise Water-Energy Penalties, J. Sustain. Dev. Energy, Water and Environ. Syst., Vol. 4, No. 2, pp 161-172, 2016, https://doi.org/10.13044/j.sdewes.2016.04.0013

4. Meggers, F., Exergy Optimized Wastewater Heat Recovery: Minimizing Losses and Maximizing Performance, Proceedings of the $8^{\text {th }}$ International Conference for Enhanced Building Operations, 2008.

5. van der Hoek, J. P., Energy from the Water Cycle: A Promising Combination to operate Climate Neutral, Water Practice \& Technology, Vol. 6, No. 2, 2011, https://doi.org/10.2166/wpt.2011.019

6. Meggers, F. and Leibundgut, H., The Potential of Wastewater Heat and Exergy: Decentralized High-temperature Recovery with a Heat Pump, Energy and Buildings, Vol. 43, No. 4, pp 879-886, 2011, https://doi.org/10.1016/j.enbuild.2010.12.008

7. Frijns, J., Hofman, J. and Nederlof, M., The Potential of (Waste) Water as Energy Carrier, Energy Conversion and Management, Vol. 65, pp 357-363, 2013, https://doi.org/10.1016/j.enconman.2012.08.023 
8. Babak, T., Khavin, G., Duić, N., Boldyryev, S. and Krajačić, G., Possibility of Heat Pump use in Hot Water Supply Systems, J. Sustain. Dev. Energy, Water and Environ. Syst., Vol. 4, No. 3, pp 203-215, 2016, https://doi.org/10.13044/j.sdewes.2016.04.0017

9. Baek, N. C., Shin, U. C. and Yoon, J. H., A Study on the Design and Analysis of a Heat Pump Heating System using Wastewater as a Heat Source, Solar Energy, Vol. 78, No. 3, pp 427-440, 2005, https://doi.org/10.1016/j.solener.2004.07.009

10. Buhler, T., Heat Recovery from Wastewater (in French), AKTUELL, pp 379-384, 2008.

11. Rognon, F., Heat Recovery in Wastewater (in French), 2009.

12. Liu, L., Fu, L. and Jiang, Y., Application of an Exhaust Heat Recovery System for Domestic Hot Water, Energy, Vol. 35, No. 3, pp 1476-1481, 2010, https://doi.org/10.1016/j.energy.2009.12.004

13. Chao, S., Yiqiang, J., Yang, Y., Shiming, D. and Xinlei, W., A Field Study of a Wastewater Source Heat Pump for Domestic Hot Water Heating, Department of Building Thermal Energy Engineering, pp 1-17, 2012.

14. Chao, S., Yiqiang, J., Yang, Y. and Shiming, D., Experimental Performance evaluation of a Novel Dry-expansion Evaporator with Defouling Function in a Wastewater Source Heat Pump, Applied Energy, Vol. 95, pp 202-209, 2012, https://doi.org/10.1016/j.apenergy.2012.02.030

15. Wong, L. T., Mui, K. W. and Guan, Y., Shower Water Heat Recovery in High-rise Residential Buildings of Hong Kong, Applied Energy, Vol. 87, No. 2, pp 703-709, 2010, https://doi.org/10.1016/j.apenergy.2009.08.008

16. Liu, L., Fu, L. and Zhang, S., The Design and Analysis of Two Exhaust Heat Recovery Systems for Public Shower Facilities, Applied Energy, Vol. 132, pp 267-275, 2014, https://doi.org/10.1016/j.apenergy.2014.07.013

17. Lund, H., Werner, S., Wiltshire, R., Svendsen, S., Thorsen, J. E., Hvelplund, F. and Mathiesen, B. V., $4^{\text {th }}$ Generation District Heating (4GDH) Integrating Smart Thermal Grids into Future Sustainable Energy Systems, Energy, Vol. 68, pp 1-11, 2014, https://doi.org/10.1016/j.energy.2014.02.089

18. Mathiesen, B. V., Lund, H. and Connolly, D., Limiting Biomass Consumption for Heating in 100\% Renewable Energy Systems, Energy, Vol. 48, No. 1, pp 160-168, 2012, https://doi.org/10.1016/j.energy.2012.07.063

19. Mikulandrić, R., Krajačić, G., Duić, N., Khavin, G., Lund, H. and Mathiesen, B. V., Performance Analysis of a Hybrid District Heating System: A Case Study of a Small Town in Croatia, J. Sustain. Dev. Energy, Water and Environ. Syst., Vol. 3, No. 3, pp 282-302, 2015, http://dx.doi.org/10.13044/j.sdewes.2015.03.0022

20. Leuenberger, M., Heating and Cooling thanks to Wastewater (in French), 2006.

21. Xiao-Yan, L. and Hai-Tao, L., Study on Reutilization of Low Level Heat Energy from Muncipal Wastewater of China, International Conference on Environmental Science and Technology, 2005.

22. Cipolla, S. S. and Maglionico, M., Heat Recovery from Urban Wastewater: Analysis of the Variability of Flow Rate and Temperature in the Sewer of Bologna, Italy, Conference of the Italian Thermal Machines Engineering Association, pp 288-297, 2013.

23. Lindstrom, H. O., Experience with a 3.3 MW Heat Pump using Sewage Water as a Heat Source, Symposium on the Large Scale Application of Heat Pumps, 1985, https://doi.org/10.1016/0198-7593(85)90119-5

24. Hazlehurst, A., Economic Analysis of Solar Power: Achieving Grid Parity, 2014.

25. MonEnergie, ELECTRICITE (May 2015), 2015.

26. Rushing, A. S., Kneifel, J. D. and Lippiatt, B. C., Energy Price Indices and Discount Factors for Life-cycle Cost Analysis, 2013. 
27. Zott, A., Lindahl, M., Nordman, R., Rivière, P. and Miara, M., Evaluation Method for Comparison of Heat Pump Systems with Conventional Heating Systems, 2011.

28. Barbier, S., Systems - Theoretical Principles for Heating and Sanitary Warm Water (in Dutch), Passive and Low-energy Buildings, $2015 .$.

29. Wanner, O., Panagiotidis, V., Clavadetscher, P. and Siegrist, H., Effect of Heat Recovery from Raw Wastewater on Nitrification and Nitrogen Removal in Activated Sludge Plants, Water Research, Vol. 39, No. 19, pp 4725-4734, 2005, https://doi.org/10.1016/j.watres.2005.09.026

30. IBGE-BIM, Energetic Review of the Brussels Capital Region 2011 (in French), 2011. 31. IBGE-BIM, Heating Degree Days (in French), 2015.

32. Royal Meteorological Institute of Belgium (in Dutch), 2016.

Paper submitted: 15.06 .2016

Paper revised: 04.11.2016

Paper accepted: 06.11.2016 